\title{
LAS VARIEDADES LINGÜÍSTICAS DEL ESPAÑOL EN LOS LIBROS ESCOLARES ARGENTINOS: ENTRE LAS POLÍTICAS DEL ESTADO Y EL MERCADO
}

\author{
LINGUISTIC VARIATIONS OF SPANISH LANGUAGE IN \\ ARGENTINIAN SCHOOL BOOKS: BETWEEN STATE POLICIES \\ AND THE MARKET
}

\author{
María López García \\ Consejo Nacional de Investigaciones Científicas y Técnicas \\ UNIVERSIDAD DE BUENOS AirES
}

RESUMEN

El trabajo analiza el caso de la compra y entrega estatal de libros por parte del Ministerio de Educación de la Nación de la Argentina como ejemplo de las políticas lingüísticas tendientes a instalar los discursos panhispánicos. La hipótesis central es que la compra masiva de libros se torna eje de la regulación de la política lingüística escolar. Para demostrarla, se expone en primer lugar la relación entre el respeto a la diversidad -sostenido en la Ley de Educación Nacional (No 26.206) - y la interpretación unificadora que las editoriales masivas trasladan a sus manuales de enseñanza del español como lengua escolar. En segundo lugar, el artículo explora las condiciones de la licitación para la compra estatal y los beneficios que representan para las editoriales transnacionales.

El corpus de trabajo se compone de una serie de manuales escolares de lengua del nivel primario y de la legislación nacional y provincial, vinculados con la enseñanza de la lengua. En el marco que ofrecen la sociolingüística (Blommaert, 2010) y la glotopolítica (Narvaja de Arnoux, 2008; Narvaja de Arnoux \& Del Valle, 2010) para entender los procesos políticos, económicos y culturales asociados a la globalización, el artículo busca determinar si la falta de una regulación explícita para la elección de materiales escolares podría repercutir en el diseño editorial de las representaciones de la lengua que la escuela transfiere a la población.

PALABRAS ClAVE: variedades del español; enseñanza del español; manuales escolares; panhispanismo; compra estatal de libros escolares 


\section{Abstract}

In this paper we examine the procurement and delivery of schoolbooks by the Ministry of Education of Argentina as an example of language policies aimed to establishing a Pan-Hispanic discourse. The central hypothesis is that the mass purchase of school books becomes the regulatory axis of school language policy. To test this hypothesis, we first examine the relationship between respect of diversity - as mandated by the National Education Law ( $N^{o}$ 26.206) — and the unifying interpretation that global publishers instill into their schoolbooks of Spanish teaching. Secondly, we discuss the bidding conditions that the government imposes for the procurement and the benefits these represent for global publishing houses.

The corpus consists of a number of primary education schoolbooks as well as national and provincial regulations related to the teaching of the Spanish language. Within the sociolinguistics (Blommaert, 2010) and glotopolitics (Narvaja de Arnoux, 2008; Narvaja de Arnoux \& Del Valle, 2010) framework, the article aims to determine whether the lack of an explicit regulation on the selection of schoolbooks could impact the editorial design of the language representations that schools transfer to the population.

KEYWORDS: Spanish variations; teaching of Spanish; schoolbooks; Pan-Hispanism; government purchases of schoolbooks

Fecha de recepción del artículo: 20 de octubre de 2015

Fecha de recepción de la versión revisada: 28 de abril de 2016

Fecha de aceptación: 28 de junio de 2016

La correspondencia relacionada con este artículo debe dirigirse a:

María López García

maguilopezgarcia@yahoo.com.ar 


\section{INTRODUCCIÓN: FORMACIÓN DOCENTE Y PAUTA CURRICULAR COMO CONDICIONES DE POSIBILIDAD}

En la Argentina la enseñanza de la lengua en los niveles obligatorios (13 años entre primaria y secundaria) responde a contenidos comunes de alcance nacional reunidos en los Núcleos de Aprendizajes Prioritarios (en adelante, NAP), regulados a su vez por diseños curriculares establecidos diferenciadamente (siempre en función de los NAP) en cada provincia. Sin embargo, las condiciones actuales de la formación docente de primaria, que tiende al modelo generalista en desmedro de la profundización disciplinar, impiden la lectura crítica de la currícula por parte de los maestros. ${ }^{1}$ En el área de lengua, concretamente, el trabajo sobre los contenidos obligatorios involucra el conocimiento de diversas metodologías, teorías lingüísticas y modelos de análisis literario, lo que no se logra en los dos cuatrimestres de formación en lengua con los que cuentan en el profesorado.

Como hemos mostrado en otro trabajo (véase López García, 2010), debido a este déficit en su formación disciplinar, los docentes se convierten en consumidores obligados de las propuestas editoriales para el trabajo en el aula. Mientras tanto, las empresas editoriales procesan e interpretan el currículum y luego ofrecen actividades que resuelven la tarea diaria con los alumnos. De este modo, la influencia que el libro de texto ejerce en la elección de los contenidos y en las

1 La estructura curricular vigente para la formación docente de primaria se divide entre 1024 horas-cátedra correspondientes al "campo de los saberes a enseñar", en el que se incluyen las didácticas de las asignaturas (lengua, matemáticas, ciencias sociales y ciencias naturales), taller de pensamiento lógico, taller de lectura, escritura y oralidad, y los "ateneos" de reflexión sobre la práctica. Estas son las únicas instancias en toda la currícula de formación en las que se conocen los contenidos de las disciplinas. Luego, un total de 1248 horas cátedra corresponden al "campo de la subjetividad y la cultura" y al "campo de la fundamentación" (que incluye las asignaturas: didáctica general; análisis del mundo contemporáneo; teorías sociopolíticas y educación; cultura, comunicación y educación; historia y prospectiva de la educación; configuraciones culturales del sujeto educativo de primaria; pedagogía crítica de las diferencias, entre otras generalidades). Finalmente, 256 horas-cátedra corresponden a las prácticas y 160 horas-cátedra al "espacio de definición institucional". (Cfr. Gobierno de la Provincia de Buenos Aires, 2008: 95-99.) En este contexto, a la formación en el área de lengua le corresponden dos cuatrimestres por todo concepto. Esa es la formación de base desde la que los docentes leen el currículum elaborado por especialistas de las disciplinas (generalmente, provenientes del ámbito superior) y a partir del cual diseñan sus programas y preparan sus clases. 
políticas lingüísticas implementadas se fortalece en un contexto de formación docente insuficiente para el procesamiento de la pauta indicada por la legislación.

En el caso específico de los contenidos obligatorios vinculados con las variedades lingüísticas regionales, la situación se profundiza debido a que el currículum de formación docente (centrado en los temas consuetudinarios y urgentes: normativa, gramática oracional y textual, géneros discursivos y ortografía) no logra incluirlos, ni atender a los modelos sociolingüísticos que abogan por la enseñanza dialectal (Rona, 1965; Leeman, 2015). El dictado de estos contenidos se resuelve entonces a partir del "sentido común" de los docentes (es decir, a partir de las representaciones sociolingüísticas que los docentes generan en tanto que hablantes de la variedad) y las propuestas de las editoriales. Es decir que, probablemente, los docentes transfieran a sus alumnos los prejuicios que entienden las variedades regionales como desvíos de la lengua estándar y que asocian el conocimiento de los modelos gramaticales con el conocimiento de la lengua.

Un profesorado con alta formación disciplinar abordaría el conocimiento de las variedades desde un modelo sociolingüístico y no desde un prejuicio, pero no es el caso (véase López García, 2010). De ahí que sea posible considerar que la interpretación editorial de los NAP constituya en sí misma una política lingüística y que entonces las políticas lingüísticas desplegadas por el Estado argentino para la enseñanza de la lengua materna deban ser analizadas en la articulación con los medios masivos vinculados con el ámbito escolar, en especial, las empresas editoriales con productos orientados a la enseñanza. Es allí donde se gestionan las representaciones sobre la lengua materna que se enseña y también, por defecto, sobre la lengua no escolarizada (o no escolarizable).

\section{INTERPRETACIÓN EDITORIAL DEL CURRÍCULUM OBLIGATORIO NACIONAL}

La Ley de Educación Nacional argentina ( $\mathrm{N}^{\mathrm{o}}$ 26.206), vigente desde el año 2006, otorga a los agentes de difusión de los contenidos curriculares la potestad de autorregularse al designar como Consejo Consultivo del Ministerio de Educación a "representantes de los medios de comunicación escritos, radiales y televisivos, de los organismos representativos de los anunciantes publicitarios y del Consejo Federal de Educación, con el objeto de promover mayores niveles de 
responsabilidad y compromiso de los medios masivos de comunicación con la tarea educativa de niños/as y jóvenes" (artículo 103, título VII, Ley № 26.206).

Esta desregulación estatal coincide con la expansión de los medios de comunicación hacia mercados internacionales y, en el caso particular que nos ocupa, de los grupos editoriales con intereses en la educación.

En relación con la enseñanza de la lengua, las decisiones de los agentes editoriales tienden a la adscripción de políticas lingüísticas funcionales a sus objetivos económicos. Los materiales producidos por estas empresas (Santillana, del Grupo Prisa; Estrada y Puerto de Palos, ambas pertenecientes al Grupo Macmillan; Aique/Larousse, Norma/Kapelusz, entre otras) son adquiridos por la Dirección Nacional de Políticas Socioeducativas (DNPS) del Ministerio de Educación y distribuidos gratuitamente en el país entre los estudiantes con menos recursos, de acuerdo con lo expresado en la ley (artículo 80, título V, Ley $\mathrm{N}^{\circ}$ 26.206). ${ }^{2}$ Con ello, la pauta lingüística de las empresas, que, como mostraremos, tiende a evitar el tratamiento de las variedades y lenguas de la región en favor de la enseñanza del español "panhispánico", podría transformarse en la pauta lingüística de la nación.

\section{LA VARIEDAD LINGÜÍSTICA EN LOS MANUALES ESCOLARES ADQUIRIDOS POR EL ESTADO}

En este apartado ejemplificaremos brevemente el despliegue discursivo en los manuales escolares de los ideologemas de la unidad, la diversidad y la intercomunicación que sustentan el modelo "panhispánico" promovido por la Real Academia Española (RAE). Dicha institución se apoya en estos pilares discursivos para afianzar su legitimidad como agente de control lingüístico. Es decir, la construcción del panhispanismo y la instauración de un agente regulador son recursos empleados para imponer discursivamente el poder de la RAE como recolectora, evaluadora y procesadora de la realidad lingüística en el mundo hispánico, y como codificadora de la forma común a todos esos registros (véase el desarrollo de esta idea en Lauria \& López García, 2009). Como lo indican los

2 Esto ocurrió así en el marco de la gestión de la presidenta Cristina Fernández de Kirchner. La nueva gestión del presidente Mauricio Macri no ha adoptado aún una política clara en relación con la compra de materiales escolares, no obstante haber recibido préstamos a tal efecto. 
prólogos tanto del Diccionario panhispánico de dudas como de la Nueva política lingüística panhispánica:

Con su reconocida autoridad en materia léxica, la Academia incorpora a su Diccionario no solo aquello que responde a lo que se ha llamado el genio de la lengua, sino, también, ajena a un purismo trasnochado, otro tipo de innovaciones y, siempre con cautela, extranjerismos a veces no acomodados a esa índole, pero ya asentados en la comunidad hispanohablante (RAE, 2001: IX).

Se diferenciaría [la Nueva Gramática de la Lengua Española] de las anteriores en la atención que debería prestar al español de América, en la línea de la nueva política lingüística panhispánica impulsada por la Real Academia Española (RAE \& Asale, 2004: 14).

Como veremos en algunos ejemplos, el libro de texto funciona como dispositivo de difusión de argumentos propios del panhispanismo. A través de definiciones y ejercicios prepara el terreno para considerar las variedades como meras particularidades superpuestas a una lengua común y, con ello, retroalimenta las condiciones de existencia de materiales de enseñanza comunes para las distintas regiones hispanohablantes. Los encargados de proveer estas herramientas educativas serán entonces los centros de regulación dotados de los medios económicos y simbólicos para gestionar instrumentos de gramatización y, con ellos, de reproducir su rol en la regulación de la lengua.

La política panhispánica sostiene la oposición entre lengua general y variantes regionales representadas exclusivamente en la prosodia y el léxico. En ese sentido, la oposición entre lengua general y variedades resulta funcional a las políticas unificadoras que alientan la "protección" de la unidad a través de una supuesta generalidad.

La división entre lengua general y lengua regional sostiene la designación de una variedad estándar o "español general", como lo muestran los instrumentos académicos de regulación del español: "El léxico actual recogido es del español general de España y América, prescindiendo de los usos regionales y locales"3 (RAE, 2011: XVIII).

3 Si bien es cierto que los términos silla o mesa están más extendidos que lejía o la preposición $a$ por, la división entre lengua general y lengua regional colabora con la idea de que las varieda- 
Léxico americano. Respondiendo a su carácter selectivo, el DICCIONARIO recoge una muestra que no pretende ser extensa, pero sí significativa, de voces de América, indicando su naturaleza por medio de las marcas adecuadas. Las marcas utilizadas en el DICCIONARIO para señalar los usos americanos son dos: “Am.” y "frecAm.”. En ningún caso se debe interpretar que la voz o la acepción así marcadas se usen en todo el ámbito americano: solo hacen referencia a que el uso se da en dos o más países del continente. La primera marca, Am., acompaña a usos exclusivamente americanos. [...] La segunda marca, frecAm., indica voces o acepciones conocidas también en España, pero mayoritarias en América (RAE, 2011: XIX). ${ }^{4}$

El espíritu panhispánico de unidad en la diversidad resulta así conveniente a los fines de sostener el control de los instrumentos de gramatización (diccionarios, gramáticas, ortografías, materiales de enseñanza, guías de corrección, manuales de estilo, etc.) o tomar decisiones estandarizadoras como crear el español neutro (la variedad de los medios de comunicación hispanos interesados en unificar al público consumidor). En efecto, el Diccionario panhispánico de dudas, elaborado por la Academia, reconoce:

Todo ello es hoy realidad gracias al generoso mecenazgo de Telefónica, que, en sintonía con su identidad de empresa de comunicación especialmente asentada en el mundo hispanohablante, vio en este proyecto un instrumento eficaz para reforzar la unidad del idioma y el complemento indispensable del servicio de "Español al día", de la Real Academia Española, que con su ayuda hace también posible (RAE \& Asale, 2005: XI).

A continuación algunos ejemplos de la aparición del discurso de la unidad en la diversidad y la reducción de la variedad al léxico en libros escolares argentinos recientes:

des son derivaciones respecto de una unidad original, de una lengua pura y uniforme, en lugar de considerar las variedades como fenómenos de frecuencia de uso.

4 Siendo que la Península alberga a un inferior número de hablantes (15\%) respecto de América, sería más económico señalar el "léxico español", en lugar del "léxico americano". 
(1) Los dialectos regionales dependen del país. Por ejemplo, en la Argentina, decimos bebé y en Bolivia, dicen guaga. Existe también un dialecto general, que se emplea en libros o periódicos de gran circulación y que es neutro. [Aique, 160] ${ }^{5}$

(2) La lengua general permite que todos los hablantes de un idioma, español en nuestro caso, se comuniquen y entiendan. Dentro de esa lengua hay variantes regionales, diferentes tonadas, palabras o expresiones distintas; por ejemplo: pibe, chango, lolo (en Chile), mita (en Paraguay), chavo (en México), botija (en Uruguay); se trata, en este caso, de lengua regional. Como ustedes habrán observado al mirar la televisión de otros países hispanohablantes o al ver una película doblada al español, en algunos casos usan el tú en situaciones en las que nosotros usamos vos, es decir, emplean el tuteo en lugar del voseo. También, esta característica marca variantes regionales. [Kapelusz, 90]

La relación entre "dialecto" (entendido como variedad regional) y "país" que presentan los ejemplos no tiene asidero teórico ni pertinencia en la actual gestión discursiva de los Estados nacionales. Sí lo tiene relacionar "dialecto" con un repertorio de regionalismos, como se evidencia también en los ejemplos de los instrumentos académicos.

El ejercicio mostrado en (3) involucra el uso de posesivos en construcción preposicional (suya/de ella) que requieren reflexión específica en la variedad y, en especial, su vínculo con la inexistencia del vosotros en América. Lo mismo sucede con la prescripción de (4), ignorante de que en la variedad del Río de la Plata el estándar indica detrás mío (mientras escribo, el corrector de Word lo reemplaza automáticamente por detrás de mî).

\section{(3) Ejercitación}

Felicitas y Agustín son hermanos. Agreguen los pronombres que faltan en el diálogo que ellos tuvieron mientras iban a la escuela.

—Felicitas, $¿ \ldots . . . . .[\mathrm{Te}]$ acordaste de pedirle a mamá el dinero para el almuerzo?

5 Los manuales que analizo aparecen citados por el nombre de la editorial y se listan al final de la nota. La decisión de no indicar los nombres de los autores de los libros de texto responde a que el recorte curricular, la extensión y profundidad asignada a los temas, la diagramación, el enfoque didáctico y, fundamentalmente, la orientación glotopolítica son responsabilidad de la empresa que contrata a los especialistas. 
$[\ldots]$

—A ver, esperá. ¿La .........[suya/de ella] tendrá créditos? [Kapelusz/Norma, 114]

(4) Errores frecuentes

Cuando hablamos o escribimos podemos cometer algunos errores. Estas expresiones inadecuadas pueden darse en distintos aspectos de la lengua. Por ejemplo [...] en lo sintáctico (detrás mío por detrás de mî). [Estrada, 164]

Ni en el libro del maestro ni en el ejercicio se brinda una explicación que pueda permitirles a los hablantes de la variedad comprender las razones que diferencian el uso de los pronombres en diferentes regiones lingüísticas. Esta falta de reflexión impacta en dos sentidos: por un lado, no se conoce la variedad; por otro, se instaura la idea de que la gramática es un aparato teórico que no se aplica a las variedades, sino a un español "general" no localizado.

\section{EL RESPETO POR LA DIVERSIDAD LINGÜÍSTICA COMO “EDUCACIÓN EN VALORES"}

Blommaert (2010) señala que la globalización no revisa las escalas de distribución del poder mundial, sino que las monta sobre una nueva organización discursiva. La globalización, en tanto que reorganización geopolítica, diseña discursos desanclados no solo de su geografía, sino también de su historia. Precisamente, en esa clave opera la estandarización de la lengua: los discursos sobre el estándar erigen ciertas marcas lingüísticas en desmedro de otras, opacando las tensiones surgidas en la operación de selección que todo estándar entraña. Según Garatea Grau (2006), cuando en 1964 Paul Gavin emplea el término estándar para reemplazar al de lengua literaria, si bien le aporta el sesgo de neutralidad "que reclama la lingüística moderna", oculta el hecho de que los estándares son resultado de una construcción histórica.

El monocentrismo que por distintas razones prácticas imperó en los discursos sobre el español en los Estados americanos postergó el conocimiento de las variedades y la generación de representaciones legitimantes de los dialectos y de instancias reguladoras americanas. En este contexto de desprestigio histórico de las variedades, percibidas por sus propios hablantes como desvíos respecto de un español "puro" o ideal, los discursos pluricéntricos operan como 
estrategias de inclusión, afianzando la idea de unidad, cuando un verdadero pluricentrismo debería alentar el conocimiento de las variedades y fortalecer nuevas instancias reguladoras regionales.

El paisaje lingüístico (Gorter, 2006) de Buenos Aires incluye lenguas originarias (toba, guaraní, quichua, wichí, etc.), de inmigración reciente (chino, coreano, etc.), de inmigraciones pasadas (italiano, alemán, idish, hebreo, etc.) y de los medios de comunicación (español neutro, español estándar porteño, inglés) entre las más salientes. En ese marco, el discurso de la diversidad permite encuadrar y fortalecer las identidades (o, al menos, organizar discursos que lo aparenten) en el arrasador campo de interpretación global de las relaciones (en nuestro caso, de las relaciones entre las lenguas) aun cuando las subsume bajo la enseñanza del español estándar transnacional (si es que eso existiera) como única lengua escolar.

Por su parte, el currículum escolar argentino retoma el topos de la diversidad y atraviesa las disciplinas con los principios del respeto y la valoración de lo diferente. Los contenidos del área de lengua no quedan al margen de estos discursos. Pero, mientras la gramática oracional y textual y la normativa son ubicadas dentro del área de influencia de la disciplina, los registros y las variedades lingüísticas se reinterpretan en la clave del respeto por los derechos humanos y la diversidad, es decir, como contenidos transversales. ${ }^{6}$ Los NAP alientan a "valorar" (no a "conocer" o "describir") la variedad, que, a su vez, se presenta como un contenido cultural (reafirmando la escisión entre lengua escolar, en tanto que gramática, y lengua regional, vinculada con los rasgos de color o folclóricos) y no como contenido disciplinar. Concordantemente, su presencia está acotada: en

6 Este solapamiento tiene larga data en la Argentina. El adoctrinamiento para el buen comportamiento fue de la mano del control lingüístico en los inicios de las prácticas educativas en el país hacia fines del siglo xix. En la actualidad algunos integrantes de la Academia Argentina de Letras continúan asociando lengua y moral:

Cuando una persona admite anárquicamente la validez de la incorrección o ni siquiera tiene conocimiento de ella, o no le importa porque está para otra cosa en esta vida, ha dejado de amarse y se convierte a sí misma, por su voluntad, en un objeto que sólo sirve para producir poco de nada. Cómplice del error o ignorante de éste, se repliega, se encierra poderosa en sus adentros, prisionera de la ansiedad y víctima de un malentendido individualismo; no se abre a la realidad de la cultura, no quiere razonar ni comprometerse con la sociedad a la que pertenece (Zorrilla, 2007). 
los NAP los contenidos correspondientes a la gramática oracional y textual y la normativa ocupan trescientas palabras y la variedad regional, trece.

La escuela ofrecerá situaciones de enseñanza que promuevan en los alumnos y alumnas durante el Segundo Ciclo de Educación General Básica (EGB)/Nivel Primario: "La valoración de la diversidad lingüística como una de las expresiones de la riqueza cultural de la región y del país" (Ministerio de Educación de la Nación, Ciencia y Tecnología, 2005: 28).

Mientras tanto, en los diseños curriculares de la Provincia de Buenos Aires la variedad se enmarca bajo el título "Las prácticas del lenguaje en los ámbitos de la participación ciudadana":

Desarrollar prácticas del lenguaje en los ámbitos de la participación y construcción de la ciudadanía implica continuar habilitando el uso de la palabra a los chicos como modo de integración social y de participación democrática. [...] Progresivamente los chicos se irán apropiando de los usos sociales del lenguaje que les permitirán participar de comunidades discursivas cada vez más amplias, e integrarse en ellas críticamente. Por ello, es esencial que la escuela tome una posición frente al tratamiento de las diferentes lenguas o de variedades de una misma lengua (Gobierno de la Provincia de Buenos Aires, 2008: 119-120).

Esta asociación entre lengua y ciudadanía, evidenciada desde los documentos curriculares y desde muchos libros de texto, es una práctica discursiva constructora de prejuicios sociales y lingüísticos, como se puede ver en (5) y (6).

(5) Prólogo del libro: "Además, la lengua es el tejido conjuntivo de la sociedad, es la vía por donde los hombres se comunican, buscan consensos y se asocian; dialogan y discuten sus ideas y proyectos. Por ello, la lengua es el pilar de una democracia verdadera". [Editorial SM, 10]

(6) Conectá valores. Una de las variedades lingüísticas estudiadas es el registro o variedad situacional. ¿Les parece que es importante poseer diversos registros a la hora de utilizar nuestra lengua? ¿Por qué? [Editorial SM, 166] 
Las deficiencias en la formación disciplinar de los maestros ( $c f r$. López García, 2010) y la instalación de una pauta lingüística global que desatiende los contenidos sobre las variedades prescriptos por la Ley de Educación y sus regulaciones curriculares se potencian con un hecho crucial: el Estado argentino compra partidas masivas de materiales producidos por las editoriales con intereses en la educación y las distribuye entre la población desfavorecida (los ejemplos que hemos analizado más arriba han sido tomados de manuales entregados por el Estado). Esto no solamente afianza al manual como dispositivo ineludible del trabajo escolar (cuestión que desarrollaremos inmediatamente), sino que difunde una ideología linguiística que contradice el espíritu de la ley que el mismo Estado argentino refrenda.

\section{EL LIBRO COMO INSTRUMENTO INELUDIBLE DEL APRENDIZAJE ESCOLAR}

Hasta el año 2016, la entrega gratuita estatal consistió en libros de texto y en textos literarios. En relación con ambos tipos de texto escolar, es interesante reponer el presupuesto (de padres y maestros) de que la posesión del libro garantiza la práctica de lectura escolar; esta vinculación olvida la necesaria intervención docente y confirma la relación sin intermediarios que las editoriales intentan construir con los alumnos a partir de estrategias lingüísticas operadas en el manual escolar.

Algunas afirmaciones de Daniel Filmus - Ministro de Educación de la Nación entre 2003 y 2007 y quien fuera el primer impulsor de las compras masivas de libros escolares para su entrega gratuita - en relación con la compra de libros para las escuelas son elocuentes acerca de la concepción imperante sobre el uso del libro y los problemas implicados en el acceso a ese bien simbólico/económico por parte de la población. ${ }^{7}$ Durante el acto de presentación del Programa Global de Compra de Libros 2004-2005, realizado el 12 de octubre de 2004, expresó:

El Gobierno Nacional realizará una inversión récord para continuar las acciones iniciadas para la incorporación del libro en el sistema educativo. [...] El

7 Según las encuestas a maestros, padres y alumnos mencionadas en Carbone \& Rodríguez (1996), la posesión de manuales de editoriales históricamente dedicadas a la educación como Santillana o Estrada representa para los padres el acceso a contenidos escolares de calidad y disminuye el riesgo de quedar a expensas de los limitados conocimientos del docente. 
haber planteado el acceso al libro como una política de Estado $^{8}$ desde que iniciamos la gestión hace que los docentes comiencen a sentirse más autorizados para exigir el uso del libro en las escuelas. Si el Estado llega [a] todos aquellos niños y jóvenes que no pueden comprar su libro, contribuirá a que el docente tenga derecho a exigir más lectura en el aula (Ministerio de Educación. Presidencia de la Nación, 2005).

Por su parte, María Beatriz Taboada, en su análisis de manuales de la Provincia de Entre Ríos, corrobora esta idea y ejemplifica con la opinión de un docente: "los chicos si no tienen un libro no leen. No leen. Entonces, así [con la posesión del libro] me favorece la lectura" (Taboada, 2006: 547).

Las afirmaciones de los docentes en las encuestas realizadas a maestros, padres y alumnos de la Provincia de Buenos Aires ( $c f r$. Carbone \& Rodríguez, 1996; Carbone \& Corduras, 2001) corroboran que el uso ineludible del libro de texto en la escuela es una premisa instalada en el imaginario didáctico. Lejos quedaron las pujas entre el Estado y los editores a propósito de la ley de edición estatal de un libro único (cfr. López García, 2015). La representación de que el docente está habilitado e incluso obligado a pedir libros entraña la idea de que el ingreso del libro, cualquiera que sea, en la escuela redundará en un beneficio para la adquisición de las prácticas de lectura. En esa misma lógica, el Estado argentino garantiza la posesión de un manual por alumno de la escuela primaria. Es más, la práctica usual de emplear el mismo manual para el trabajo con todos los alumnos es afianzada con la entrega gratuita por parte del Estado del mismo libro para los alumnos del mismo año. Lo cierto es que el manual facilita la tarea del maestro, pero también unifica y prefigura las tareas a tal punto que

8 Según datos presentados por Alfonso de Guzmán, gerente del área de Educación para América Latina y especialista en textos escolares del Banco Mundial, al año 2005

se estima que los proyectos de educación incluyen con más frecuencia algún componente de dotación de textos escolares. Hasta 1990 solo un $48 \%$ de los proyectos presentados incluía la dotación de los libros de texto en sus objetivos. En el periodo comprendido entre 1996 y 2000, un 66\% de los proyectos de educación han incluido en sus objetivos la dotación de textos escolares; esto demuestra que al menos una parte significativa de los gobiernos considera que los textos escolares son un eje fundamental para el desarrollo de la educación. Del total del presupuesto entregado a la educación se pasó de invertir un 4\% en textos escolares en el año 1990 a 10\% en el 2000 (Uribe, 2005: 69). 
termina por convertirse en el instrumento de programación de los contenidos y de las estrategias didácticas para vehicularlos (en sus páginas web las editoriales garantizan a los docentes el apoyo mediante guías con recursos tales como cuadros de contenido, proyectos de lectura, "solucionarios", actividades de refuerzo, e incluso glosas para los actos patrios, entre otros). El Estado pierde entonces no solo el control sobre la interpretación de los contenidos comunes, sino también sobre la construcción de la clase.

El problema no es nuevo, el informe de la Comisión Especial del año 1940 —integrada, entre otros especialistas, por Berta Vidal de Battini, investigadora del equipo que Amado Alonso ${ }^{9}$ había formado en el Instituto de Filología de la Universidad de Buenos Aires (cfr. López García, 2012) — ya anticipaba concordantemente que:

la previsión oficial, sin embargo, no había contemplado hasta ahora en su verdadero alcance este aspecto fundamental del problema del libro escolar. Es sabido, en efecto, que solo existían acerca del mismo disposiciones fragmentarias y generalmente de carácter impreciso. Esto hizo que la preparación del material quedara librada al criterio particular del autor [...] La realización del libro se convirtió de este modo, por obvia razón, en tarea de fácil estímulo y poco riesgo, que invitaba a la improvisación. Como consecuencia lógica de todo ello, la producción, con desmedro de la calidad, se multiplicó notablemente en los últimos años, hasta llegar al estado de cosas actual (Consejo Nacional del Educación, 1941: 21).

La puja entre editoriales y Estado argentino tiene más de 100 años ( $c f r$. López García, 2015). En la actualidad, los intereses económicos puestos en juego en esa relación y el modo en que estas condiciones repercuten en los contenidos de lengua dejan expuesto el hecho de que toda política lingüística (por acción o por defecto) se delinea en una lucha de intereses en tensión. Como ejemplo de los factores involucrados en la contienda, en los próximos apartados daremos cuenta

9 Amado Alonso (1896-1952) fue uno de los discípulos de Ramón Menéndez Pidal y dirigió el Instituto de Filología de la Universidad de Buenos Aires. Su gestión, que se extendió desde 1927 hasta 1946, favoreció la formación de investigadores de primera línea en el campo de la lingüística, la filología y la crítica literaria; la investigación sobre los dialectos de la Argentina; la producción de importantes publicaciones; la transferencia de conocimientos al ámbito docente, y la renovación de los contenidos escolares de lengua. El Instituto lleva su nombre desde 1963. 
de las condiciones de la compra masiva de libros escolares en la Argentina y las regulaciones de las que han sido objeto por parte del Estado nacional.

\section{FACTORES EN TENSIÓN EN LA COMPRA ESTATAL DE LIBROS DE TEXTO}

\subsection{Partidas presupuestarias para compra de libros escolares}

El acceso a la información sobre las licitaciones y las compras resulta engorroso porque no está disponible en la página de la DNPS ni en el Centro Nacional de Información y Documentación Educativa (Cenide),${ }^{10}$ ni tampoco se obtiene información en entrevistas a funcionarios. Hemos podido, no obstante, recopilar de distintas fuentes algunos datos orientativos. En los informes del Banco Interamericano de Desarrollo (BID), prestatario de los fondos con los que se adquieren los materiales, se recoge que entre 2002 y 2004 al "Programa de mejoramiento del sistema educativo argentino" le correspondieron 1200 millones de dólares que pagaron en partes iguales el BID y el Estado nacional. A la dotación de textos escolares se le asignó un 4.3\% (51.9 millones de dólares) (cfr. Uribe, 2005).

La página web del DNPs, ${ }^{11}$ actualizada hasta julio de 2015 (montos actualizados hasta el año 2011), indica que durante el primer semestre de 2011 se distribuyeron 9444173 libros, lo que significó una inversión de 204861662 pesos (48 millones de dólares).

Dos años más tarde, una circular emanada desde el Ministerio detalla las partidas presupuestarias destinadas a los libros: "Se invertirán 320 millones de pesos [45 millones de dólares en ese año, aproximadamente] para la distribución de más de 13 millones de libros en escuelas públicas de todo el país [...] que involucra a 77 editoriales, 35 imprentas, 10 imprentas con talleres de encuadernación, y 30 talleres de encuadernación y cosido" (DNPS, 2013). Aunque no se especifica en qué porcentaje se beneficiará a las editoriales nacionales y extranjeras, ni qué relación de dependencia las unen a imprentas y talleres.

En 2015, a través de un comunicado, el Ministro de Educación de la Nación, Alberto Sileoni, anunció el inicio de la distribución de 6400000 libros de

${ }^{10}$ El Cenide alberga toda la legislación generada por el Ministerio nacional desde los comienzos del sistema educativo.

11 Véase http://portales.educacion.gov.ar/dnps/ 
texto en el marco del Operativo Nacional de Entrega de Textos y Libros Escolares 2015. La medida,

que beneficiará a 8.400 escuelas primarias y casi 6.000 secundarias de todo el país, representa una inversión superior a los 431 millones de pesos [47 millones de dólares aproximadamente]. [...] El Ministerio distribuirá 6.380.805 millones de libros de 19 editoriales, entre las que se incluyen, además de grandes grupos editores, pequeñas empresas nacionales y sellos pertenecientes a universidades públicas. Del operativo 2015 participan Aique, Aula Taller, AZ, Edebé, Estación Mandioca, Estrada, Eudeba, Fundación Edelvives, Kapelusz, Letra Impresa, Longseller, Macmillan, Maipue, Nazhira, Puerto de Palos, Santillana, SM, Universidad de General Sarmiento y Vicens Vives. ${ }^{12}$

En términos de capacidad de compra, el mismo monto en dólares en 2015 representa la mitad que en 2011. Sin embargo, la presencia de estos materiales, en conjunto con la entrega gratuita de netbooks, artículos de librería, colecciones audiovisuales provenientes del medio virtual estatal educ.ar, la producción de libros de apoyo docente generados por el Ministerio y la amplia difusión de la señal de cable "Paka-paka", otorgaron en los últimos años mucha visibilidad a los apoyos materiales otorgados por el Estado.

Lo que resulta central evaluar en estos casos es si el destino de los fondos genera un beneficio a mediano y largo plazos para la industria del libro nacional y, en el caso particular de los contenidos de los libros de lengua, si la independencia respecto de las editoriales transnacionales permitiría forjar actitudes positivas hacia las variedades locales escolares. Por eso es fundamental determinar cuáles son las editoriales favorecidas por el Estado y cuál es la posición político lingüística que sustenta sus propuestas.

\subsection{Condiciones de participación en las licitaciones}

Tal como confirman algunos comunicados del Ministerio y las bibliotecas destinatarias de los envíos, los beneficiarios directos de las partidas presupuestarias

12 Véase http://www.universidadeshoy.com.ar/despachos.asp?cod_des=63015\&ID_Seccion $=183 \&$ fecemi=29/06/2015\&Titular=sileoni-ldquofelizmente-podemos-decir-que-el-libro-le-estaacute-ganando-a-la-fotocopia-en-las-aulas-argentinasrdquo.html 
para compra de manuales escolares son los grupos editoriales con recursos suficientes para participar de las licitaciones, muchos de ellos pertenecientes a grupos económicos transnacionales.

En la licitaciones llevadas a cabo hasta 2016, los postulantes debían presentar (en el mes de septiembre del año anterior al que saldrían al mercado) treinta manuales terminados, en las condiciones materiales exactas en las que se publicarían de ser seleccionados por el Ministerio. Estos requisitos (ver detalles en López García, 2016) acotaban la participación a las pocas empresas en posesión de un equipo de autores, editores, diseñadores e insumos que permitieran hacer esa apuesta. Esto resulta en que son las editoriales que integran grupos transnacionales las que acceden en un mayor porcentaje a la compra estatal masiva.

Entre las editoriales beneficiadas se cuentan Aique (parte del grupo Larousse y Alianza), Santillana (Grupo Prisa), Estrada, Puerto de Palos (Macmillan), Kapelusz (Norma, Carbajal educación), sm (Grupo español sM, Fundación Santa María, con presencia en América Latina) y Fundación Edelvives (fundada en España en el Instituto Marista de Enseñanza), entre otras.

Lo cierto es que las resoluciones que rigen la selección de manuales que el Ministerio hace para luego distribuirlos entre la población socialmente vulnerable - el propósito de la DNPS es "fortalecer las trayectorias educativas de niños, niñas y jóvenes en contextos socioeconómicos vulnerables a través de la asignación de los recursos necesarios" 13 — no establece cuál es la pauta lingüística a la que deberá atender el material. De ahí el libre albedrío de las editoriales en la interpretación de los NAP y los diseños curriculares de cada provincia. Como señalábamos más arriba, la labilidad en la formulación de los contenidos abre un espacio para la interpretación tendiente a intereses transnacionales que finalmente son los privilegiados con la compra masiva de los materiales que la vehiculan.

Por su parte, las editoriales de fondos nacionales como Longseller, Estación Mandioca o Letra Impresa, entre otras, cuyo peso simbólico en el mercado de los textos escolares no está todavía instalado, tienen en sus manos la compleja decisión de plegarse a la pauta (en nuestro caso, la pauta lingüística) de la mayoría o elaborar contenidos que requerirán de un esfuerzo docente y a los que los padres tildarán, en el mejor de los casos, de progresistas.

${ }^{13}$ Véase http://portales.educacion.gov.ar/dnps/acerca-de/ 
El reaseguro que brinda el Ministerio para que la selección siga los lineamientos curriculares y también atienda a las representaciones que los maestros (y/o profesores) tienen de la tarea que los incumbe y su relación con los libros escolares es conformar comisiones de selección integradas por docentes.

\section{SELECCión DE LiBRos ESCOLARES, ¿QUIÉN CONTROLA LA POLÍTICA LINGÜÍSTICA DEL ESTADO ARGENTINO?}

Para la compra de libros se implementa una secuencia administrativa destinada a legitimar el destino de las partidas que hemos mencionado más arriba. Por medio de resoluciones, el Ministerio llama a licitación para la compra de libros escolares (en mayor medida, literatura infantil y juvenil, y libros de texto).

En concordancia con la búsqueda de transparencia en el proceso de selección de libros escolares, la DNPS, a través de su página web, pone a disposición nombre y currículum de los integrantes de la Comisión Asesora Nacional (CAN) y las Comisiones Asesoras Provinciales (CAP). Los libros presentados por las editoriales son evaluados por especialistas de diferentes áreas disciplinares pertenecientes a las distintas jurisdicciones educativas del país: la CAN y las distintas CAP, integradas por maestros, especialistas en educación y expertos de las disciplinas. Es decir que cada jurisdicción designa representantes que deberán contemplar los acuerdos federales así como las pautas curriculares y didácticas de la jurisdicción por la que han sido escogidos.

Los currícula disponibles en 2015 en la página de la DNPS para la ciudad de Buenos Aires corresponden a cuatro especialistas para el área de lengua, de los cuales solo uno tiene un título de la disciplina y una especialización en literatura. ${ }^{14}$

14 a. Profesora para la enseñanza primaria (1977)/Profesora para la enseñanza del adulto y adolescente (1994).

b. Profesora de enseñanza primaria (1982)/Bibliotecaria escolar (1996)/Editora (2008)/Postítulo en educación de adultos y adolescentes (2006)/Postítulo en educación de imágenes y medios (2008) / Gestión educativa (2010).

c. Profesora de educación tecnológica (1988)/Bibliotecario escolar-bibliotecario profesional (2004).

d. Profesorado para la Enseñanza Primaria Normal (1977)/Bibliotecaria Escolar (1991)/Profesorado de Castellano, Literatura y Latín (1988)/Postítulos Especialista en Literatura Infantil (2005). 
Por su parte, los currícula correspondientes a los profesionales que seleccionan los libros para la Provincia de Buenos Aires son tres, solo uno de ellos tiene formación (terciaria) con base en el área de lengua. ${ }^{15}$

En ninguna de las instancias de control real de esos materiales (es decir, ni en los pliegos de la licitación, las pautas de selección nacional y provincial, ni los especialistas responsables de la tarea) se prevé la necesidad de acordar una política lingüística sobre la lengua española (indicada como lengua obligatoria de esos materiales), ni de que haya un lingüista evaluando esos materiales.

Consecuentemente, no solo no hay una política lingüística uniforme (o concertada) en los materiales que se entregan, sino que además muchos de estos instrumentos incluso pueden llegar a relativizar los contenidos comunes expresados en los NAP y en los diseños curriculares de la Ciudad y la Provincia de Buenos Aires, como se vio en los ejemplos mostrados más arriba.

\subsection{Algunas repercusiones del proceso de selección}

Durante el año 2013 se suscitó un malestar entre los docentes mendocinos en relación con algunas obras seleccionadas por la CAN y la CAP (en acuerdo al mecanismo antes detallado) y enviadas a las escuelas de la provincia. Los textos observados fueron El inspector injusto y otras historias, de Sanyú (historieta con tema policial, en la que hay desnudos y escenas violentas propios del género), Sin novedad en el frente, de Patricia Breccia (un diario apócrifo también presentado con la estructura de novela gráfica, género del cual solo suelen presentarse a los estudiantes tiras cómicas agrupadas) y Peter Capusotto, el libro (escrito sobre el modelo de un programa de sketches de la TV pública, que durante esos años tuvo mucha aceptación entre los jóvenes porteños), de Diego Capusotto y Pedro Saborido. Los diarios mendocinos (iProfesional y La Razón) reprodujeron esta molestia con título catástrofe:

15 a. Licenciada y Profesora en Ciencias de la Educación (1972).

b. Profesora en Ciencias de la Educación (1989)/Especialización en Escritura y Alfabetización (2012).

c. Profesora de enseñanza secundaria, normal y especial en Letras (1984). 
Escándalo: el Gobierno envió a escuelas libros de editorial $\mathrm{K}^{16}$ con contenido sexual explícito (Eleisegui, 2013).

Escándalo en Mendoza: entregan libros escolares con sexo explícito. Los docentes comenzaron una campaña de denuncia y sacaron de circulación las publicaciones, enviadas por el Ministerio de Educación de la Nación, como material de lectura. Contenían violencia, lesbianismo, zoofilia, lenguaje vulgar, uso de drogas y burlas a la Iglesia (Anónimo, 2013.)

Esta posición acerca del contenido del material es consistente con las observaciones de integrantes porteños y bonaerenses de la CAP, quienes no siempre encuentran en las comisiones de otras provincias la apertura estética que demanda seleccionar textos literarios con fines no solo formativos, sino también recreativos y estimulantes de hábitos de consumo culturales.

Apenas conocido el conflicto, el Ministerio envió rápidamente una circular con fecha 7 de agosto de 2013 justificando el procedimiento de selección de títulos del "Operativo Nacional de Entrega de Libros", realizado en 2010 y sustanciado el corriente año. La circular destacó el federalismo de la CAN y las razones disciplinares y didácticas que avalaron la selección.

Como mencionábamos antes, entre las funciones que cumple la entrega gratuita de materiales está la de organizar y facilitar la tarea docente. Sin embargo, la insuficiente formación de base que el Estado provee a los maestros convierte a estos materiales en la única fuente autorizada del saber. Con una restricción: ese discurso constitutivo, apoyado en el discurso científico ( $c f r$. Maingueneau \& Cossutta, 1995), deberá ir a favor de las representaciones que los docentes tienen de los contenidos a transmitir. En caso contrario, los docentes contrastarán las

${ }^{16}$ En estos medios se acusó a Aurelio Narvaja, dueño de la editorial Colihue e integrante del grupo intelectual "Carta Abierta" (cercano al gobierno de Néstor y Cristina Fernández de Kirchner, de ahí la acusación de " $K$ " de los materiales), de haber sido favorecido con la compra masiva de sus materiales. Este argumento ignora, por un lado, la histórica relación entre esa editorial (surgida a comienzos de los años ochenta) y la lectura escolar. Las colecciones "Leer y crear", "El pajarito remendado", "Libros del malabarista", entre otras, de la editorial, albergan obras premiadas y autores reconocidos y son clásicos de las bibliotecas escolares. Por otro, olvidan que los grupos económicos dueños de los diarios que se hicieron eco del escándalo también poseen editoriales escolares que han recibido millones de pesos del mismo Ministerio para sus tiradas de miles de manuales escolares. 
diferentes propuestas e irán en búsqueda del manual que acompañe sus representaciones. Esto explica el rechazo de materiales "progresistas", como en el caso de los libros entregados en Mendoza, independientemente de que estos se ajusten a los contenidos comunes nacionales o presenten propuestas surgidas de contextos académicos de producción de conocimiento. Las reacciones ponen de manifiesto no solo representaciones acerca de la lengua que se enseña y de las corrientes teóricas aceptables en el ámbito escolar, sino también de la función docente como filtro de las propuestas tanto del Ministerio como de las editoriales. En ese sentido, en tanto que destinatarios principales de las propuestas de los manuales, los docentes se tornan agentes centrales. Al carecer de formación lingüística específica que les permita trascender su rol de hablantes en la gestión de representaciones de la lengua y seleccionar el acercamiento gramatical hacia la lengua materna, quedarán a merced de quienes les acerquen propuestas claras para su tarea diaria.

En el caso de los libros de lengua, el impacto que tienen las representaciones sociolingüísticas enseñadas o evocadas en los alumnos (maestros y padres) y la validación que el Estado opera con su compra acaban por convertirlos en el principal agente de gestión y transmisión de las ideas sobre la lengua nacional.

\section{Conclusiones}

A lo largo del trabajo hemos querido mostrar en qué sentido la compra y entrega estatal de libros se torna eje de la regulación político lingüística del español que se enseña en la escuela. En la articulación entre el Estado y las editoriales de venta masiva confluyen, por un lado, las necesidades administrativas de instalar y desplegar en el territorio el libro de texto y, por otro lado, los propósitos económicos apoyados en la ideología lingüística llamada panhispánica. Si bien la Ley de Educación Nacional expresa un espíritu de respeto de la diversidad, las editoriales, intérpretes y difusoras de los contenidos escolares de y en lengua española fundan su ejercicio en la atención a sus necesidades económicas y a políticas lingüísticas transnacionales. Estas condiciones, potenciadas por la ausencia de una política lingüística en las licitaciones, en el personal encargado de su selección y en las condiciones de formación de los docentes que implementarán las propuestas, terminan convirtiendo a la inacción estatal en liberación del espacio de regulación lingüística ( $c f r$. Calvet, 1996). Este laissez faire resulta fun- 
cional a modelos lingüísticos que entienden la diversidad como un conjunto de rasgos subordinados a una lengua común. Estos hechos representan un problema de soberanía (linguiística) en tanto la ejecución de decisiones de importancia glotopolítica se gestiona en ámbitos transnacionales y pone en juego partidas millonarias provenientes de préstamos europeos.

\section{Manuales citados}

AiQue (2008). Lengua y prácticas del lenguaje 6. Buenos Aires: Aique.

Editorial sm (2011). Prácticas del lenguaje 3. (Serie Conecta 2.0). Buenos Aires: SM.

Estrada (2008). Lengua 6. (Col. Andamios). Buenos Aires: Estrada.

Kapelusz (2007). Lengua 5, 6, 7. (Serie del Molino). Buenos Aires: Kapelusz.

Kapelusz/Norma (2009). Lengua 6. (Serie del faro). Buenos Aires: Kapelusz/Norma.

\section{REFERENCIAS}

ANónimo (2013). Escándalo en Mendoza: entregan libros escolares con sexo explícito. La razón, 8 de agosto. Recuperado de http://archivo.larazon.viapais.com.ar/actualidad/Escandalo-Mendoza-entregan-escolares-explicito_0_485400165.html (Consulta: 10 de julio, 2015).

Blommaert, Jan (2010). The Sociolinguistics of globalization. Cambridge: Cambridge University Press.

Calvet, Louis-Jean (1996). Las políticas lingüísticas. Buenos Aires: Edicial.

Carbone, Graciela M., \& Corduras, Luisa (2001). El libro de texto en la escuela. Buenos Aires: Universidad Nacional de Luján/Miño y Dávila.

Carbone, Graciela M., \& Rodríguez, Luis María (1996). El libro de texto en la escuela (tomo I). Buenos Aires: Universidad Nacional de Luján.

Congreso de la Nación (2006). Ley de Educación Nacional No 26.206. Recuperado de http:// www.me.gov.ar/doc_pdf/ley_de_educ_nac.pdf

Consejo Nacional de Educación (1941). Estudio, selección y concurso de textos de lectura. Buenos Aires: Talleres Gráficos del Consejo Nacional de Educación.

Dirección Nacional de Políticas Socioeducativas (DNPS) (2013). Más libros y colecciones literarias. Recuperado de http://portales.educacion.gov.ar/dnps/noticias/operativo-nacional-de-entrega-de-textos-escolares/

Eleisegui, Patricio (2013). Escándalo: el Gobierno envió a escuelas libros de editorial 'K' con contenido sexual explícito. iProfesional, 8 de agosto. Recuperado de http://www.iprofesional. 
com/notas/167060-Escandalo-el-Gobierno-envio-a-escuelas-libros-de-editorial-K-con-contenido-sexual-explicito (Consulta: 10 de julio, 2015).

Garatea Grau, Carlos (2006). Pluralidad de normas en el español de América. Revista Internacional de Lingüística Iberoamericana, 4(7), 141-158.

Gobierno de la Provincia de Buenos Aires (2008). Diseño curricular para la educación primaria. Segundo Ciclo. Buenos Aires: Dirección General de Cultura y Educación. Recuperado de http://servicios.abc.gov.ar/lainstitucion/organismos/consejogeneral/disenioscurriculares/documentosdescarga/diseniocurricularparaeducacionprimaria2ciclo.pdf

GORTER, DURK (2006). The study of the linguistic landscape as a new approach to multilingualism. International Journal of Multilingualism, 3(1), 1-6.

Lauria, Daniela, \& López García, María (2009). Instrumentos lingüísticos académicos y norma estándar del español: la nueva política lingüística panhispánica. Lexis, 33(1), 49-89.

LeEman, Jennifer (2015). Identity and heritage language education in the United States. Annual Review of Applied Linguistics: An Official Journal of the American Association for Applied Linguistics, 35, 100-119.

López García, María (2010). A rey muerto, rey puesto. El papel del docente en el manual escolar. Revista Iberoamericana de Educación, 54, 203-220. Recuperado de http://www.rieoei. org/rie54a10.pdf

López García, María (2012). La enseñanza de la lengua escolar como proyecto de identidad nacional: el contexto socio educativo. Revista Argentina de Historiografía Lingüística, 4(2), 117-132. Recuperado de http://www.rahl.com.ar/index.php/rahl/article/view/55

López García, María (2015). Nosotros, vosotros, ellos. La variedad rioplatense en los manuales escolares. Buenos Aires: Miño y Dávila.

López García, María (2016). Compra estatal de libros escolares. Afinidades electivas entre el Estado argentino y las editoriales multinacionales. Línguas e Instrumentos Linguísticos, 37, 29-52.

Maingueneau, Dominique, \& Cossutta, Frédéric (1995). L'analyse des discours constituants. Langages, 29(117), 112-125.

Ministerio de Educación (2012). Resolución NN 1613 "Bases para la selección de textos escolares para el $7^{\circ}$ año de la educación primaria y para el ciclo básico de la educación secundaria".

Ministerio de Educación de la Nación, Ciencia y Tecnología (2005). Núcleos de aprendizajes prioritarios: $2^{o}$ ciclo EGB/nivel primario. Buenos Aires: Consejo Federal de Cultura y Educación.

Ministerio de Educación. Presidencia de la nación (2005). El ministerio de Educación ya distribuyó 3.500.000 textos y duplicará la compra de libros para el 2005. Recuperado de http:// portal.educ.ar/noticias/educacion-y-sociedad/el-ministerio-de-educacion-ya.php 
Narvaja de Arnoux, Elvira (2008). Ámbitos para el español: recorridos desde una perspectiva glotopolítica. Reverte. Revista de Estudos e Reflexões Tecnológicas da Faculdade de Tecnologia da Indaiatuba, 6, 1-28. Recuperado de http://www.fatecid.com.br/reverte/index.php/ revista/article/view/25/29

Narvaja de Arnoux, Elvira, \& Del Valle, José (2010). Las representaciones ideológicas del lenguaje: discurso glotopolítico y panhispanismo. Spanish in Context, 7(1), 1-24.

Real ACademia Española (RAe) (2001). Diccionario de la lengua española. Madrid: Espasa.

Real Academia Española (rae) (2011). Diccionario del estudiante. Madrid: Santillana.

Real Academia Española (rae) \& Asociación de Academias de la Lengua Española (Asale) (2004). La nueva política lingüística panhispánica. III CILE. Rosario: República Argentina.

Real Academia Española (rae) \& Asociación de Academias de la Lengua Española (AsaLE) (2005). Diccionario panhispánico de dudas. Bogotá: Santillana.

Rona, José Pedro (1965). Relación entre la investigación dialectológica y la enseñanza de la lengua materna. Programa interamericano de lingüística y enseñanza de idioma, Simposio de Cartagena, agosto de 1963: informes y comunicaciones. Bogotá: Instituto Caro y Cuervo.

Taboada, María Beatriz (2006). Profesionalidad docente y libros de texto, un acercamiento discursivo a estrategias de construcción identitaria. En Hispanismo: discursos culturales, identidad y memoria (pp. 545-552). San Miguel de Tucumán: Universidad Nacional de Tucumán.

Taboada, María Beatriz (2011). Nombrar el país: imágenes del interior y de la capital en libros de texto de Lengua y Ciencias Sociales. Paraná: Fundación La Hendija.

URIBE, RichARD (2005). Programas, compras oficiales y dotación de textos escolares en América Latina. Bogotá: Centro Regional para el Fomento del Libro en América Latina y el Caribe, Unesco. Recuperado de http://www.cerlalc.org/secciones/libro_desarrollo/Textos_Escolares.pdf

Zorrilla, Alicia (2007). La estética de las palabras. Santiago del Estero: Fundación Cultural Santiago del Estero. Recuperado de http://www.fundacioncultural.org/revista/nota6_34.html 